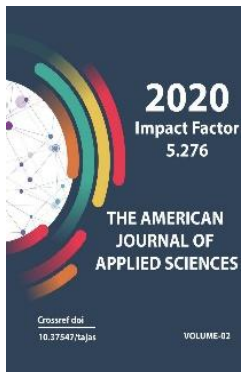

Copyright: Original content from this work may be used under the terms of the creative commons attributes 4.0 licence.

\section{The Role Of Human Healthy And Safe Lifestyle In The Period Of Global Pandemic-Covid 19}

\author{
Ochilova Nurbibi Rakhimova \\ Senior Lecturer Of The Faculty Of Natural Sciences, Bukhara State University, Uzbekistan \\ Tolibova Zevar Hojiyevna \\ Lecturers Of The Faculty Of Natural Sciences, Bukhara State University, Uzbekistan \\ Karshiyeva Dilovar Rustamovna \\ Lecturers Of The Faculty Of Natural Sciences, Bukhara State University, Uzbekistan
}

\title{
ABSTRACT
}

This article discusses the role and actuality of human health and safe lifestyle in the period of global outbreak as well as provides the simplest tips on maintaining daily healthy and safe lifestyle.

\section{KEYWORDS}

Safety; safety of human life; healthy lifestyle; human life, global outbreak

\section{INTRODUCTION}

Today, the populations of the world countries including our county's people are suffering from Covid-19 in the period of global pandemic. We understand well that there is no such person in the world whose life would be completely fenced off from dangers. As long as our life exists, dangers threaten not only a person, but also society, the state and the whole world. We know that human life is the most valuable thing gifted by god. Therefore,

security today is still the same urgent problem as it was many years ago, as not only individuals, but also states, countries, nations and the whole world should take part in its solution. 


\section{MATERIALS AND METHODS}

It is impossible to ensure the absolute security of a person, society and state. Based on the analysis of Internet resources, several definitions of the safety of human life were identified, since many authors and scientists interpret this concept in different ways. The safety of a person's life is his ability to recognize and foresee danger in everyday life in order to avoid it or minimize its consequences. The safety of a person's life is such a state of his body throughout life when the action of external and internal factors does not lead to death or illness and does not interfere with the achievement of certain goals desirable for a person. The safety of human life is the study of the problem of dangers that threaten a person, society, the state, the whole world, and the development of appropriate methods of protection against them. The solution to the problem of life safety is to ensure comfortable living conditions for people, to protect a person from the effects of harmful environmental factors that exceed the normative permissible levels. Ensuring the safety of work and rest of a person helps to increase his life expectancy, preserve his mental and physical health. The fundamental formula for the safety of human life is the search, prevention and elimination of any potential danger. The Constitution of the Republic of Uzbekistan was adopted on December 8, 1992. It includes chapters which define the basic principles and content of the activities of citizens of our country to ensure the security of the state, public security, environmental safety, personal security, and other types of security provided for by the legislation of the Republic of Uzbekistan, the powers and functions of all state authorities in the field of security. Today, the study of the safety of human life is based on the perceived need of society in warning against dangers, on the rules of safe behavior of the state and its inhabitants, as well as on the observance of the laws prescribed in the Constitution of the Republic of Uzbekistan. A feature of the study of the safety of human life is that it cannot be investigated by the methods of particular sciences or by a simple summation of their methods. It covers a whole spectrum of sciences that rely on completely different aspects of life. Throughout its development, humanity has been constantly faced with the problem of ensuring security. Thanks to the progress that changed the world, the well-being of people has increased the quality of life and their working conditions have improved, the production of industry and agriculture has reached unprecedented proportions, especially in economically developed countries.

The destructive effect of many technologies and chemicals increased, huge losses of people and economic damage were noted. The safety of every person and their environment must be considered taking into account all economic, social and environmental consequences.

\section{RESULTS AND DISCUSSIONS}

Having discussed above, we can say that security today must become a part of the lifestyle of every individual. The safety of a person's life also lies in maintaining a healthy lifestyle - in nutrition, sports and relations with others. We will present a list of practical recommendations for preventing potential health hazards and well-being below.

\section{Stage 1: Getting rid of bad habits}

Any bad habit might be smoking, alcoholism or even the habit of going to bed late - all this undoubtedly leaves a huge imprint on our health. And getting rid of them will be the first step towards preventing hazards. According 
to the World Health Organization, 50\% of the "strength" of health depends entirely on a person's lifestyle, and a person without bad habits lives on average 14 years more than someone who has addictions.

\section{Stage 2: Healthy eating}

The point of healthy eating is simple and straightforward: food should contain a maximum of nutrients:

- $\quad$ Minimum salt and sugar

- $\quad$ More fresh fruits and vegetables

- $\quad$ Complete rejection of fast food

- $\quad$ Drink more purified, still water

- $\quad$ Eat fermented milk products

- Add poultry and fish to the diet distribute the right amount of calories every day and time. You should not gorge yourself at night, but breakfast should be as nutritious as possible so that you have enough energy for the whole day. It should be remembered that homemade food is much healthier than the so-called fast food (all kinds of hamburgers, sandwiches, etc.) and instant convenience foods. Fresh products, steamed and baked, are of maximum value. Fried and smoked foods will contain more harmful substances than useful ones. All foods with added sugar, baked goods, as well as semi-finished products and all kinds of canned food should be excluded from the diet. Increasingly, you can see gluten-free products on store shelves that can replace regular ones - this will also be beneficial.

\section{Stage 3: Active lifestyle}

Diseases and ailments of a modern person come primarily from a sedentary lifestyle. In most cases, we usually sit at a computer, at work, or TV, resting after work. Both have a detrimental effect on the human nervous system, as well as on his visual organs, which subsequently impairs the quality of life. Some of the recommendations that can help dilute a sedentary lifestyle:

1. You need a healthy sleep - at least 8 hours

2. Do exercises in the morning, as well as do gymnastics for the eyes

3. More often be in nature

4. Exercise or athletics Move and you need to do more sports: go from work and to work on foot or, even better, by bike. Spend more time in the fresh air.

\section{Stage 4: Control of health - mental and physical}

Body care is also an integral part of a healthy life. This is not only good for your health, but also pleasing to yourself. First of all, body care begins directly with personal hygiene. It is necessary to take a shower at least twice a day. In addition, it is very useful to visit the bathhouse or sauna occasionally.

\section{CONCLUSION}

In conclusion, we can say that sports and fitness should become an integral part of life and we can also try yoga to stabilize our mental health. Medical examinations need to be done more often than once a year (preferably once every six months) in order to identify the disease in the early stages and cure it.

\section{REFERENCES}

1. Nazarova E.N, Zhilov Yu. D. Fundamentals of a healthy lifestyle. M.: Academy, 2013.

2. Ochilova N.R, Muratova G.S, Sharafuddinova R.I, Manual for university students "Safety of life activities" T.:2009

3. Lutovina E.E. Forming a culture of life safety of schoolchildren in the modern educational space / E.E. Lutovina, I.A. 
Novikov // Pedagogy: family -schoolsociety: monograph / under total. ed. O.I. Kirikov. - Voronezh: VGPU, 2014.Vol. 32.

4. Matchin A.A. Healthy lifestyle and its components: studies. Manual / G.A. Matchin Orenburg: Publishing house of the OGPU, 2013

5. Yusupovich, K. S. (2020). The Emergence of Religious Views is Exemplified By The Southern Regions. The American Journal of Social Science and Education Innovations, 2(10), 143145 . 